\title{
Management of rhinosinusitis in Dutch general practice
}

\author{
*Ruth Hoffmans ${ }^{a}$, Tjard Schermer ${ }^{b}$, Chris van Weel ${ }^{b}$, Wytske Fokkens ${ }^{a}$ \\ a Department of Otorhinolaryngology, Academic Medical Centre, Amsterdam, The Netherlands \\ ${ }^{\mathrm{b}}$ Department of Primary and Community Care, Nijmegen Medical Centre, Radboud University, Nijmegen, The Netherlands
}

Received 18th June 2010; revised 26th July 2010; accepted 28th July 2010; online 10th February 2011

\begin{abstract}
Aims: To determine whether general practitioners (GPs) distinguish between the management of acute rhinosinusitis (ARS) and chronic rhinosinusitis (CRS), especially with regard to prescription of antibiotics and nasal steroids.

Methods: A questionnaire on the management of rhinosinusitis was sent to 1000 GPs in the Netherlands.

Results: Ninety-six percent discriminated between ARS and CRS. However, the definition of ARS and CRS varied. The percentage of GPS prescribing antibiotics rose as rhinosinusitis severity increased. The prescription rate of nasal corticosteroids was highest for CRS (88.6\%). Prescribing nasal corticosteroids in ARS was not very common.

Conclusions: Most GPs discriminate between ARS and CRS and 54\% accepted (the EP3OS-defined) 12 weeks as the division between ARS and CRS. Antibiotics and nasal steroids are commonly used agents, but the management of rhinosinusitis is not always consistent with guidelines.

(C) 2011 Primary Care Respiratory Society UK. All rights reserved.

R Hoffmans et al. Prim Care Respir J 2011; 20(1): 64-70

doi:10.4104/pcrj.2010.00064
\end{abstract}

Keywords acute rhinosinusitis, chronic rhinosinusitis, primary care, antibiotics, nasal steroids, guidelines.

\section{See linked editorial by Levy on pg 11}

The full version of this paper, with online Appendix,

is available at www.thepcrj.org

\section{Introduction}

Rhinosinusitis is defined as a sudden onset of two or more symptoms, one of which should be either nasal blockage or nasal discharge (anterior or posterior nasal drip). Other symptoms are facial pain or pressure, and impairment or loss of smell. When these symptoms are present for less than 12 weeks, this defines acute rhinosinusitis (ARS). When symptoms are present for more than 12 weeks, this represents chronic rhinosinusitis (CRS). ARS can be divided into two groups: common cold/acute viral rhinosinusitis (symptoms disappear in less than 10 days); and acute non-viral/bacterial rhinosinusitis (increase of symptoms after five days or persistent symptoms after 10 days). ${ }^{1-3}$

In the Netherlands, general practitioners (GPs) generally use the rhinosinusitis management guidelines from the Dutch
College of General Practitioners ${ }^{4}$ which does not distinguish between ARS and CRS. Treatment is based on the severity of symptoms and the risk of developing complications. The guideline advises treating symptoms initially and states that antibiotics are not indicated for a normal course of rhinosinusitis. Local steroids can be tried in patients with an abnormal course or recurrent complaints. ${ }^{4}$

The European guideline, The European Position Paper on Rhinosinusitis and Nasal Polyps (EPOS) advises distinguishing between ARS and CRS and basing management on the severity of the disease. Depending on severity, the recommendation for mild ARS (common cold) is to treat symptoms, with nasal steroids being advised in moderate cases. Antibiotics are added only when there are severe symptoms (fever $>38^{\circ} \mathrm{C}$, severe pain). The first choice treatment in the management of CRS is local steroids. ${ }^{1,2}$

In a cross-sectional study covering 174 GPs from 89 general practices in the Netherlands, $50 \%$ of antibiotic prescriptions were prescribed for respiratory disorders. ${ }^{5,6}$ Twenty-two percent of the antibiotics for respiratory tract infections (RTIS) were

\footnotetext{
* Corresponding author: Mrs Ruth Hoffmans, Department of Otorhinolaryngology , Academic Medical Centre, Meibergdreef 9, Amsterdam, 1105
} AZ, The Netherlands. Tel: +31205663789 E-mail: r.hoffmans@amc.uva.nl 
prescribed for rhinosinusitis. ${ }^{6}$ The prescription rate in sinusitis-like complaints was $67-70 \% .7 .8$ In another study, the antibiotic prescription rate in rhinosinusitis was $80 \%,{ }^{9}$ and prescription rates for sinus infection in the UK are $91 \%-92 \% .{ }^{10,11}$ Dutch prescription percentages for outpatient antibiotic use are relatively low compared with international figures. ${ }^{12-14}$

It has been theorised that, by reducing the inflammatory response and mucosal swelling, a topical steroid may promote drainage and increase aeration of the sinuses, hasten the elimination of infectious organisms, and reduce the frequency and severity of recurrences. ${ }^{15}$ Several studies have concluded that nasal steroids (in combination with antibiotics or alone) are beneficial in ARS and equally or more effective than antibiotics. ${ }^{15-18}$ Furthermore, nasal steroids are the treatment of first choice in CRS. ${ }^{2,19}$

Recently available data are based on general practice registries in which no distinction is made between ARS and CRS. As a result, we are not able to determine whether GPs distinguish between ARS and CRS. ${ }^{20}$

The objective of this study, therefore, was to determine whether GPs distinguish between the management of ARS and CRS, and how Dutch GPs manage these two diseases (especially with regard to the prescription of antibiotics and nasal steroids).

\section{Methods}

\section{Study design}

The Netherlands institute for health services research (NIVEL) was contacted for a random sample of 1000 Dutch GPs (the total GP population on 1 January 2007 was 8,67321). A questionnaire on the management of ARS and CRS was developed by the authors of EPOS and sent to these 1000 GPs. All the GPs were given an ID number to determine which GP returned the questionnaire. When GPs did not respond to the first mailing, a second questionnaire was sent three weeks later.

\section{Questionnaire (see Appendix A at www.thepcrj.org)}

The questionnaire consisted of three parts:

1. GP characteristics (kind of practice, age etc.)

2. A question on whether the GP differentiated between ARS and CRS

3. Two different questionnaires about the management of rhinosinusitis:

a) One for GPs differentiating between ARS and CRS

b) One for non-differentiating GPS

GPs were asked to fill out parts 1 and 2 and, depending on the answer to question 2, either part 3a or 3b.

The questionnaire consisted mainly of multiple-choice questions to facilitate participation. The questions about management of rhinosinusitis were sub-divided into questions about three categories:

- Mild rhinosinusitis: symptoms present for less than five days or improving thereafter

- Moderate rhinosinusitis: persistent symptoms after 10 days or worsening symptoms after five days

- Severe rhinosinusitis: persistent symptoms after 10 days or worsening. The GPs ranked their different treatment options from 1 to 10 (most often (1) - least often (10)). Since the ranks of the different treatment options were not normally distributed, we calculated the median rank per treatment option to describe the GPs' treatment preferences within the severity categories.

\section{Analysis}

Data were analysed with SPSS (Statistical Package for the Social Sciences) 16.0. We received information about the characteristics (sex, kind of practice, age and years of practice) of all Dutch GPs from the NIVEL to decide whether the characteristics of the GPS included in this study were representative of the entire GP population.

\section{Results}

Five hundred questionnaires were returned (a response rate of $50 \%$ ). Twenty-nine GPs refused to participate, 46 GPs completed parts 1 and 2 only, 395 filled out the complete questionnaire, and 26 forgot to complete parts 1 and 2 but did fill out part 3a or b. Four GPs said they discriminated between ARS and CRS, but completed part $3 b$ instead of $3 a$ (Figure 1). Four duplicate cases (IDs) were found in the responders. Since we did not know which were the right questionnaires, we used both in our analysis.

Most of the parameters of the responder GPs (who returned the questionnaire) were comparable to the nonresponders (GPs who did not respond). Of the responders, $33 \%$ worked in a group practice, but this figure was $60 \%$ for the non-responders $(p=0.000)$. Furthermore, the responders worked more often alone or in a practice with one other GP than the non-responders. The only age group in which there was a significant difference between responders and non-

Figure 1. Organogram.

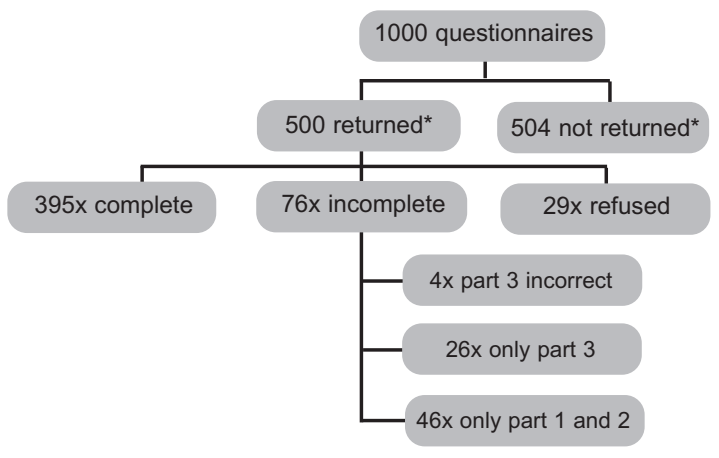

* Four questionnaires were returned twice 
R Hoffmans et al.

\begin{tabular}{|c|c|c|}
\hline & Responders \% & Non-responders $\%$ \\
\hline Male & $68 \cdot 2$ & $71 \cdot 3$ \\
\hline Female & $31 \cdot 8$ & $28 \cdot 7$ \\
\hline Solopractice & $33 \cdot 9^{*}$ & $16 \cdot 3$ \\
\hline Duopractice & $33 \cdot 5^{*}$ & $23 \cdot 5$ \\
\hline Grouppractice & $32 \cdot 6^{*}$ & $60 \cdot 2$ \\
\hline Aged $<30$ years & $0 \cdot 4$ & 0.0 \\
\hline Aged $30-34$ years & $4 \cdot 0$ & $3 \cdot 2$ \\
\hline Aged $35-39$ years & $14 \cdot 6^{*}$ & $8 \cdot 3$ \\
\hline Aged $40-44$ years & $14 \cdot 4$ & $15 \cdot 4$ \\
\hline Aged $54-49$ years & $16 \cdot 2$ & $14 \cdot 7$ \\
\hline Aged $50-54$ years & $19 \cdot 8$ & $24 \cdot 1$ \\
\hline Aged $55-59$ years & $19 \cdot 3$ & $22 \cdot 1$ \\
\hline Aged $60-64$ years & $10 \cdot 8$ & $11 \cdot 0$ \\
\hline Aged $\geq 65$ years & 0.4 & $1 \cdot 3$ \\
\hline$<5$ years of practice & $15 \cdot 5^{*}$ & $6 \cdot 1$ \\
\hline 5-10 years of practice & $17 \cdot 3$ & $19 \cdot 8$ \\
\hline $10-15$ years of practice & $15 \cdot 5$ & $16 \cdot 2$ \\
\hline $15-20$ years of practice & $13 \cdot 1$ & $12 \cdot 8$ \\
\hline $20-25$ years of practice & $13 \cdot 3$ & $15 \cdot 8$ \\
\hline$>25$ years of practice & $25 \cdot 2$ & $29 \cdot 3$ \\
\hline
\end{tabular}

Figure 2. Duration of symptoms to be considered CRS.

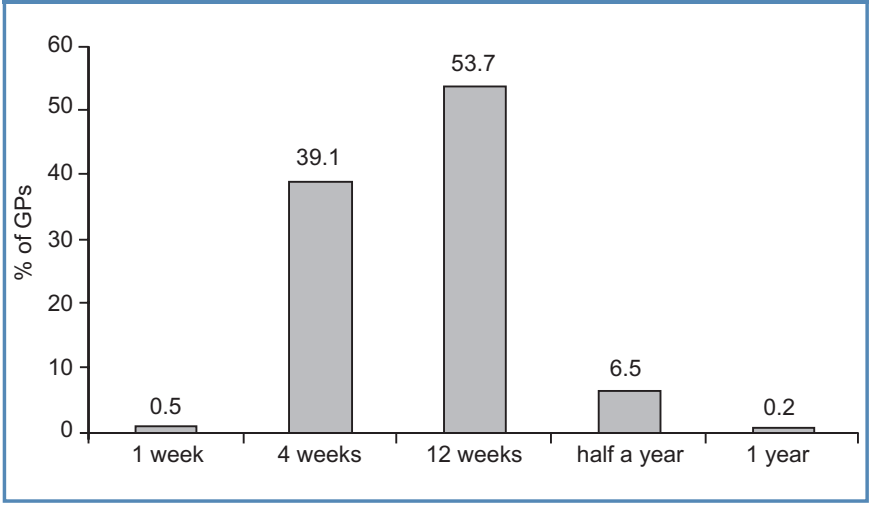

\section{Table 2. Treatment of mild ARS.}

\begin{tabular}{|c|c|c|c|}
\hline \multicolumn{4}{|c|}{ Mild ARS \% } \\
\hline No treatment & 20 & $48 \cdot 5$ & \\
\hline Treatment & & $51 \cdot 5$ & \\
\hline$\%$ & prescribing & Median rank ${ }^{\S}$ & $\%$ first choice \\
\hline Decongestives & $91 \cdot 3$ & $1 \cdot 0$ & $61 \cdot 2$ \\
\hline Painkillers & $65 \cdot 8$ & $2 \cdot 0$ & $37 \cdot 2$ \\
\hline Steaming & $55 \cdot 8$ & $2 \cdot 0$ & $18 \cdot 4$ \\
\hline Nasal douche & $31 \cdot 7$ & $2 \cdot 0$ & $34 \cdot 9$ \\
\hline Oral antibiotics & $20 \cdot 6$ & $4 \cdot 0$ & $2 \cdot 6$ \\
\hline Nasal steroids & $19 \cdot 4$ & $3 \cdot 0$ & $2 \cdot 6$ \\
\hline Oral antihistamine & $6 \cdot 9$ & $4 \cdot 0$ & 0.0 \\
\hline Mucolytics & $5 \cdot 1$ & $4 \cdot 0$ & $9 \cdot 1$ \\
\hline Systemic steroids & $3 \cdot 2$ & $9 \cdot 0$ & 0.0 \\
\hline Other & $2 \cdot 8$ & $2 \cdot 5$ & $16 \cdot 7$ \\
\hline Alternative treatment & $2 \cdot 3$ & $2 \cdot 0$ & $20 \cdot 0$ \\
\hline Topical antibiotics & $2 \cdot 3$ & $6 \cdot 5$ & 0.0 \\
\hline
\end{tabular}

there is no need for radiology in diagnosing ARS. Opinions differed for CRS: $39 \%$ still agreed there was no need for radiology, but $54 \%$ usually arranged an X-ray, $2 \%$ suggested a CT scan and $5 \%$ proposed something else.

Do you treat patients with mild acute rhinosinusitis? Of the differentiating group, 51.5\% treated patients with mild ARS. They prescribed decongestives most frequently (91.3\%). Decongestives had a median rank of 1 (first-choice treatment). $20.6 \%$ of the GPs prescribed oral antibiotics. However, only $2.6 \%$ of them reported that antibiotics were their first choice treatment. The median rank for prescribing antibiotics was 4 . Nasal steroids were prescribed by $19.4 \%$ of the GPs and the median rank was 3 (see Table 2). Again, only $2.6 \%$ of them reported nasal steroids to be their first-choice treatment. 
Table 3. Treatment of moderate ARS.

\begin{tabular}{|c|c|c|c|}
\hline & \multicolumn{3}{|c|}{ Moderate ARS \% } \\
\hline No treatment & \multicolumn{3}{|c|}{$17 \cdot 5$} \\
\hline Treatment & \multicolumn{3}{|c|}{$82 \cdot 5$} \\
\hline & $\%$ prescribing & Median rank $^{\S}$ & $\%$ first choice \\
\hline Decongestives & $83 \cdot 5$ & $1 \cdot 0$ & $59 \cdot 5$ \\
\hline Painkillers & $62 \cdot 3$ & $2 \cdot 0$ & $38 \cdot 7$ \\
\hline Steaming & $45 \cdot 2$ & $2 \cdot 0$ & $22 \cdot 2$ \\
\hline Nasal steroids & $37 \cdot 3$ & $2 \cdot 5$ & $21 \cdot 7$ \\
\hline Oral antibiotics & $34 \cdot 0$ & $3 \cdot 0$ & $17 \cdot 2$ \\
\hline Nasal douche & $28 \cdot 5$ & $2 \cdot 0$ & $21 \cdot 5$ \\
\hline Oral antihistamine & $7 \cdot 2$ & $4 \cdot 0$ & 0.0 \\
\hline Mucolytics & $5 \cdot 1$ & $5 \cdot 0$ & 0.0 \\
\hline Systemic steroids & $2 \cdot 7$ & $10 \cdot 0$ & 0.0 \\
\hline Alternative treatment & $1 \cdot 8$ & $9 \cdot 0$ & $20 \cdot 0$ \\
\hline Topical antibiotics & $1 \cdot 8$ & $9 \cdot 0$ & $16 \cdot 7$ \\
\hline Other & 0.9 & $10 \cdot 0$ & $33 \cdot 3$ \\
\hline
\end{tabular}

\section{Do you treat patients with moderate acute} rhinosinusitis?

Most (82.5\%) of the differentiating GPs treated patients with moderate rhinosinusitis. Decongestives were most frequently prescribed and were their first choice treatment. Antibiotics were prescribed by $34 \%$ of the GPs, and ranked third. $17.2 \%$ of the GPs prescribing antibiotics reported this treatment to be their first choice. An even higher percentage (37.3\%) prescribed nasal steroids (median rank 2.5). Of these GPs, $21.7 \%$ said that nasal steroids were their preferred treatment (see Table 3).

\section{Do you treat patients with severe acute} rhinosinusitis?

Nearly all GPs in the differentiating group treated patients with severe ARS (99\%). Antibiotics were most frequently prescribed $(84 \%) .39 .1 \%$ of the GPs prescribing antibiotics reported antibiotics to be their first choice. The median rank for prescribing antibiotics was 2 , but there was no median rank 1 . The most commonly prescribed antibiotic in mild, moderate and severe (A)RS was doxycycline. Nasal steroids were prescribed by $28 \%$ of the GPs treating severe ARS; $14.7 \%$ of them said that nasal steroids was their first choice treatment. The median rank for nasal steroids was 3 (see Table 4).

When do you refer patients with moderate (acute) rhinosinusitis to a specialist?

Almost half of the GPs (46.5\%) said that they never refer these patients to a specialist. One-third reported referring after four weeks of treatment without improvement. $6 \%$ referred after two weeks of treatment without improvement, and $1.5 \%$
Table 4. Treatment of severe ARS.

\begin{tabular}{|c|c|c|c|}
\hline & \multicolumn{3}{|c|}{ Severe ARS \% } \\
\hline No treatment & \multicolumn{3}{|c|}{1.0} \\
\hline Treatment & \multicolumn{3}{|c|}{$99 \cdot 0$} \\
\hline & $\%$ prescribing & Median rank $^{\S}$ & $\%$ first choice \\
\hline Oral antibiotics & $84 \cdot 0$ & $2 \cdot 0$ & $39 \cdot 1$ \\
\hline Decongestives & $75 \cdot 5$ & $2 \cdot 0$ & $34 \cdot 8$ \\
\hline Painkillers & $75 \cdot 4$ & $2 \cdot 0$ & $47 \cdot 7$ \\
\hline Steaming & $40 \cdot 2$ & $3 \cdot 0$ & $15 \cdot 2$ \\
\hline Nasal steroids & $28 \cdot 0$ & $3 \cdot 0$ & $14 \cdot 7$ \\
\hline Nasal douche & 23 & $3 \cdot 0$ & $14 \cdot 5$ \\
\hline Oral antihistamine & $5 \cdot 1$ & $5 \cdot 0$ & $15 \cdot 0$ \\
\hline Systemic steroids & $4 \cdot 8$ & $5 \cdot 0$ & 0.0 \\
\hline Mucolytics & 3.5 & $5 \cdot 0$ & $8 \cdot 3$ \\
\hline Topical antibiotics & $2 \cdot 3$ & $4 \cdot 5$ & $25 \cdot 0$ \\
\hline Other & (8) 1.3 & $10 \cdot 0$ & $33 \cdot 3$ \\
\hline Alternative treatment & $1 \cdot 3$ & $10 \cdot 0$ & $20 \cdot 0$ \\
\hline
\end{tabular}

referred after one unsuccessful course of antibiotics. The rest had other policies for referring these patients.

When do you refer patients with severe (acute) rhinosinusitis to a specialist?

One-third of the GPs from the differentiating group referred after two weeks of treatment without result. $17.9 \%$ did this after four weeks and $14.2 \%$ after one course of antibiotics. $10 \%$ never referred and $11.4 \%$ did after 48 hours if there was no effect from nasal steroids and/or antibiotics. Two GPs $(0.5 \%)$ always referred.

When do you refer patients with ocular or neurological complications to a specialist?

Most of the differentiating GPs always referred to a specialist (87.8\%). 2\% reported referring after two weeks of treatment without improvement and 3.5\% after 48 hours if there was no effect from nasal steroids and/or antibiotics. $1.7 \%$ referred after one course of antibiotics that did not work, $0.5 \%$ never referred and $4.5 \%$ did something else.

\section{Do you treat patients with CRS?}

Seventeen GPs (4.2\%) did not treat these patients. Four of them always referred these patients to a specialist. The 95.8\% who did treat patients with CRS prescribed nasal steroids most frequently (88.6\%). Of these, $71.3 \%$ reported nasal steroids as their preferred treatment. They ranked nasal steroids first. Antibiotics were prescribed by $41.3 \%$ of the GPs, $36.9 \%$ of whom preferred this treatment above others. The median rank of antibiotics was 2 (see Table 5).

When do you refer patients with CRS to a specialist? Over half of the differentiating GPs (60.8\%) reported referring 
R Hoffmans et al.

\begin{tabular}{|c|c|c|c|}
\hline & \multicolumn{3}{|c|}{ CRS $\%$} \\
\hline No treatment & \multicolumn{3}{|c|}{$4 \cdot 2$} \\
\hline Treatment & \multicolumn{3}{|c|}{$95 \cdot 8$} \\
\hline & $\%$ prescribing & Median rank $^{\S}$ & $\%$ first choice \\
\hline Painkillers & $47 \cdot 5$ & $2 \cdot 0$ & $28 \cdot 9$ \\
\hline Nasal steroids & $88 \cdot 6$ & $1 \cdot 0$ & $71 \cdot 3$ \\
\hline Oral antibiotics & $41 \cdot 3$ & $2 \cdot 0$ & $36 \cdot 9$ \\
\hline Oral antihistamine & $24 \cdot 5$ & $2 \cdot 0$ & $4 \cdot 5$ \\
\hline Decongestives & $22 \cdot 2$ & $2 \cdot 0$ & $22 \cdot 9$ \\
\hline Nasal douche & $19 \cdot 1$ & $2 \cdot 0$ & $15 \cdot 9$ \\
\hline Steaming & $14 \cdot 2$ & $3 \cdot 0$ & $14 \cdot 9$ \\
\hline Systemic steroids & $9 \cdot 3$ & $3 \cdot 0$ & $16 \cdot 1$ \\
\hline Mucolytics & $3 \cdot 9$ & $4 \cdot 0$ & $0 \cdot 0$ \\
\hline Other & $2 \cdot 1$ & $3 \cdot 5$ & 0.0 \\
\hline Alternative treatment & $2 \cdot 1$ & $6 \cdot 5$ & 0.0 \\
\hline Topical antibiotics & $2 \cdot 1$ & $10 \cdot 0$ & $28 \cdot 6$ \\
\hline
\end{tabular}

after four weeks of treatment without improvement. 15\% referred after two weeks of treatment, $2 \%$ never referred, $1.7 \%$ always referred to a specialist, and $1.2 \%$ referred after one unsuccessful course of antibiotics. The others (19.2\%) had various other strategies like "on demand of the patient" or "in case of recurrence".

When do you want patients with CRS to visit you again for reassessment after you start therapy?

Most of the GPs (55.6\%) wanted their patients to come back after two weeks and $38.7 \%$ after four weeks. Five GPs (1.3\%) reassessed after 48 hours and $4.4 \%$ after 12 weeks.

\section{Discussion}

ARS and CRS may both be termed "rhinosinusitis", meaning "inflammation of the nose and sinuses". However, for clinical and research purposes, differentiation between these entities is preferable. Although far from being completely understood, pathological mechanisms in ARS and CRS are better understood today and begin to allow us to differentiate these diseases in terms of their cytokine profile, pattern of inflammation, and their remodelling processes. ${ }^{2}$ It is therefore important to distinguish ARS from CRS because these two disease entities seem to have different underlying aetiologies and pathogenesis.

Although an earlier study did not allow us to determine whether GPs differentiated between ARS and CRS, ${ }^{20}$ this study proves that they do ( $96 \%$ did differentiate). It is surprising that GPs do differentiate, given that the Dutch College of General Practitioners guideline does not distinguish between
ARS and CRS. ${ }^{4}$ In fact, a guideline for chronic rhinosinusitis that will make this distinction is being developed by (among others) otorhinolaryngologists and GPs. ${ }^{22}$

In this study, the duration of symptoms after which the GPs consider the condition to be CRS is not consistent. EPOS recommends a period of 12 weeks. ${ }^{2}$ Approximately half the GPs surveyed said that they used 12 weeks as their criterion. The period used by the rest varied.

Almost no GPs use radiology for diagnosing ARS, which is in accordance with current guideline advice. ${ }^{2,4}$ The conclusion of a Dutch randomised controlled trial in 1997 was that, for patients with acute maxillary rhinosinusitis presenting to general practice, an initial radiographic examination is not necessary. ${ }^{23}$ This study also concluded that antibiotic treatment (with amoxicillin) did not improve the clinical course of rhinosinusitis presenting in general practice. ${ }^{23}$ Acute rhinosinusitis will often resolve in most patients without antibiotic treatment, even if it is bacterial in origin. ${ }^{23-26}$ Common clinical signs and symptoms cannot identify patients with rhinosinusitis for whom treatment with antibiotics is clearly justified. Antibiotics are not justified even if a patient reports symptoms persisting for more than 7-10 days. ${ }^{26}$

Data from Jacobs et al. demonstrate the continued evolution of bacterial resistance due to the overprescribing of antibiotics and highlight the need for limiting the unnecessary prescription of antimicrobials in community-acquired respiratory tract infections (RTIS). ${ }^{27}$ It has been shown that countries with high levels of consumption have higher rates of antibiotic resistance. ${ }^{13}$ Although the antibiotic prescription rate in the Netherlands is extremely low compared to most European countries, and Dutch GPs do well, ${ }^{12-14}$ a considerable amount of antibiotics is still used unnecessarily. In our study, GPs consider prescribing antibiotics for mild to moderate acute rhinosinusitis, whilst the guidelines recommend otherwise. The results of recent randomised controlled trials constitute a firm scientific basis for restrictive antibiotic prescription behaviour. ${ }^{23,25}$ Initial management can be limited to symptom treatment. ${ }^{4,23}$

The EPOS guidelines consider symptoms lasting for less than five days, or improving thereafter, to constitute a common cold - in which case symptomatic treatment is advisable. When symptoms worsen after five days or persist after 10 days, a distinction is made between moderate and severe ARS. Severe ARS is ARS with fever $>38^{\circ} \mathrm{C}$ and/or severe pain. For moderate rhinosinusitis, topical steroids are advised, and antibiotics and nasal steroids are advised for severe ARS. ${ }^{2}$ These recommendations are based on recent studies showing that additional nasal corticosteroids are as effective as, or more effective than, antibiotics. ${ }^{15-18}$ This provides a welcome alternative to antibiotics without the negative consequences of microbial resistance. In the Dutch 
College of General Practitioners guideline, local corticosteroids are advised only after the failure of other treatment, in persistent or recurring complaints, or in patients with an abnormal course of rhinosinusitis. ${ }^{4}$

Corticosteroid prescription for moderate and severe ARS in our study was not very common. Only a third of the GPs in our study considered prescribing corticosteroids in moderate or severe ARS. We would like to see a higher prescription rate for the treatment of moderate and severe ARS.

In the Dutch College of General Practitioners and the EPOS guidelines, immediate referral is recommended in the presence of alarming symptoms such as periorbital oedema, displaced globe, double vision, ophthalmoplegia, reduced visual acuity, severe unilateral or bilateral headache, frontal swelling, signs of meningitis or focal neurological signs. ${ }^{2,4}$ It is worrying that $12.2 \%$ of the differentiating GPs do not refer immediately. Patients can still die of complications of ARS. ${ }^{28}$

According to the Dutch College of General Practitioners, referral should be considered when there is an abnormal disease course that does not respond to treatment or does not respond sufficiently. ${ }^{4}$ EPOS suggests considering referral when there is no improvement after 14 days of treatment in moderate ARS. In severe ARS cases, GPs should refer if there is no improvement in 48 hours. $^{2}$ In the general practices studied, only $6 \%$ of the GPs referred patients with moderate ARS in accordance with the EPOS recommendations.

In our study, more than half of the GPs arranged a plain $X$-ray in CRS cases. The sensitivity of plain film radiography when detecting sinus opacification is unacceptably low for the ethmoid, frontal and sphenoid sinuses compared to a CT scan. ${ }^{29}$ Especially in chronic rhinosinusitis - where mucosal thickening alone may be present - the drawback of overlapping structures makes evaluation of the osteomeatal complex, anterior ethmoid sinus, middle meatus and sphenoid sinus limited. ${ }^{30}$ Plain $X$-rays are therefore not advisable for CRS.

For the treatment of CRS, EPOS advises GPs to prescribe nasal steroids, to advise nasal douching, and to prescribe antihistamines if the patient is allergic. ${ }^{2}$ In this study, in CRS, the prescribing rate for nasal steroids is rather high (88.6\%). Patients with CRS are referred to a specialist - as recommended in EPOS (after four weeks of treatment without improvement) - by $60.8 \%$ of the differentiating GPs. ${ }^{2}$ EPOS advises the re-evaluation of CRS after 4 weeks ${ }^{2}$ and $38.7 \%$ of the GPs report doing this.

The study questionnaire asks GPs what they say they do, but does not check what they actually do. In an earlier study we studied morbidity registrations used by Dutch GPs; we found that $91 \%$ of the GPs prescribed medication, 3\% referred to a specialist and $8 \%$ applied for radiology. ${ }^{20}$

In conclusion, GPs do not seem to differentiate between
ARS and CRS in the way described in EPOS. Their management of rhinosinusitis is not very consistent. It would be interesting to find out whether patients with rhinosinusitis benefit more from compliance with the EPOS guideline than when GPs make their own decisions about the choice of treatment. We are therefore planning to conduct a randomised study to compare outcomes in patients with ARS presenting to general practice. If compliance with the EPOS guideline proves more effective in treating rhinosinusitis, changes may be required to the Dutch College of General Practitioners guideline.

\section{Conflict of interest declarations}

There are no conflicts of interest.

\section{References}

1. Ah-See KW, Evans AS. Sinusitis and its management. BMJ 2007; 334(7589):358-361.

2. Fokkens $\mathrm{W}$, Lund $\mathrm{V}$, Mullol J. European position paper on rhinosinusitis and nasal polyps 2007. Rhinol Supp/ 2007;(20):1-136

3. Rosenfeld RM, Andes D, Bhattacharyya N, et al. Clinical practice guideline: adult sinusitis. Otolaryngol Head Neck Surg 2007;137(3 Suppl):S1-31. http://dx.doi.org/10.1016/j.otohns.2007.06.726

4. De Sutter A, Burgers JS, De Bock GH, et al. [Dutch College of General Practitioners practice guideline rhinosinusitis]. Huisarts en Wetenschap 2005; 48:615-24.

5. Akkerman AE, Kuyvenhoven MM, Verheij TJ, van DL. Antibiotics in Dutch general practice: nationwide electronic GP database and national reimbursement rates. Pharmacoepidemiol Drug Saf 2008;17(4):378-83.

6. Ong DS, Kuyvenhoven MM, van DL, Verheij TJ. Antibiotics for respiratory, ear and urinary tract disorders and consistency among GPs. J Antimicrob Chemother 2008;62(3):587-92. http://dx.doi.org/10.1093/jac/dkn230

7. Akkerman AE, van der Wouden JC, Kuyvenhoven MM, Dieleman JP, Verheij TJ. Antibiotic prescribing for respiratory tract infections in Dutch primary care in relation to patient age and clinical entities. J Antimicrob Chemother 2004; 54(6):1116-21. http://dx.doi.org/10.1093/jac/dkh480

8. Akkerman AE, Kuyvenhoven MM, van der Wouden JC, Verheij TJ. Prescribing antibiotics for respiratory tract infections by GPs: management and prescriber characteristics. Br J Gen Pract 2005;55(511):114-18.

9. Akkerman AE, Kuyvenhoven MM, van der Wouden JC, Verheij TJ. Determinants of antibiotic overprescribing in respiratory tract infections in general practice. J Antimicrob Chemother 2005;56(5):930-6. http://dx.doi.org/10.1093/jac/dki283

10. Ashworth M, Latinovic R, Charlton J, Cox K, Rowlands G, Gulliford M. Why has antibiotic prescribing for respiratory illness declined in primary care? A longitudinal study using the General Practice Research Database. J Public Health (Oxf) 2004;26(3):268-74. http://dx.doi.org/10.1093/pubmed/fdh160

11. Ashworth M, Charlton J, Ballard K, Latinovic R, Gulliford M. Variations in antibiotic prescribing and consultation rates for acute respiratory infection in UK general practices 1995-2000. Br J Gen Pract 2005;55(517):603-08.

12. Ferech M, Coenen S, Malhotra-Kumar $S$, et al. European Surveillance of Antimicrobial Consumption (ESAC): outpatient quinolone use in Europe. $J$ Antimicrob Chemother 2006;58(2):423-7. http://dx.doi.org/10.1093/jac/dkl183

13. Goossens $H$, Ferech $M$, Vander SR, Elseviers $M$. Outpatient antibiotic use in Europe and association with resistance: a cross-national database study. Lancet 2005;365(9459):579-87.

14. Goossens H, Ferech M, Coenen S, Stephens P. Comparison of outpatient systemic antibacterial use in 2004 in the United States and 27 European 
R Hoffmans et al.

countries. Clin Infect Dis 2007;44(8):1091-5. http://dx.doi.org/10.1086/512810

15. Barlan IB, Erkan E, Bakir M, Berrak S, Basaran MM. Intranasal budesonide spray as an adjunct to oral antibiotic therapy for acute sinusitis in children. Ann Allergy Asthma Immunol 1997;78(6):598-601. http://dx.doi.org/10.1016/ S1081-1206(10)63223-1

16. Bachert C, Meltzer EO. Effect of mometasone furoate nasal spray on quality of life of patients with acute rhinosinusitis. Rhinology 2007;45(3):190-6.

17. Dolor RJ, Witsell DL, Hellkamp AS, Williams JW, Jr., Califf RM, Simel DL. Comparison of cefuroxime with or without intranasal fluticasone for the treatment of rhinosinusitis. The CAFFS Trial: a randomized controlled trial. JAMA 2001;286(24):3097-3105.

18. Meltzer EO, Bachert $C$, Staudinger $H$. Treating acute rhinosinusitis: comparing efficacy and safety of mometasone furoate nasal spray, amoxicillin, and placebo. I Allergy Clin Immunol 2005;116(6):1289-1295. http://dx.doi.org/10.1016/j.jaci.2005.08.044

19. Lund VJ, Black JH, Szabo LZ, Schrewelius C, Akerlund A. Efficacy and tolerability of budesonide aqueous nasal spray in chronic rhinosinusitis patients. Rhinology 2004;42(2):57-62.

20. Hoffmans R, Schermer T, van der Linde K, van Weel C, Fokkens W. Chronic Rhinosinusitis is not recognized by Dutch General Practitioners; A study based on morbidity registrations. 2009. Ref Type: Unpublished Work

21. Hingstman L, Kenens RJ. Cijfers uit de registratie van huisartsen - Peiling 2008, NIVEL 2008. 2008. Ref Type: Report

22. Nederlandse Vereniging voor KNO-heelkunde en Heelkunde van het HoofdHalsgebied. Conceptrichtlijn Chronische Rhinosinusitis en Neuspoliepen. 2611-2007. Ref Type: Unpublished Work
23. van Buchem FL, Knottnerus JA, Schrijnemaekers VJ, Peeters MF. Primary-carebased randomised placebo-controlled trial of antibiotic treatment in acute maxillary sinusitis. Lancet 1997;349(9053):683-687. http://dx.doi.org/10.1016/ S0140-6736(96)07585-X

24. Snow V, Mottur-Pilson C, Hickner JM. Principles of appropriate antibiotic use for acute sinusitis in adults. Ann Intern Med 2001;134(6):495-7.

25. Stalman W, van Essen GA, van der Graaf Y, de Melker RA. The end of antibiotic treatment in adults with acute sinusitis-like complaints in general practice? A placebo-controlled double-blind randomized doxycycline trial. $\mathrm{Br} J$ Gen Pract 1997;47(425):794-9.

26. Young J, De SA, Merenstein D, et al. Antibiotics for adults with clinically diagnosed acute rhinosinusitis: a meta-analysis of individual patient data. Lancet 2008; 371(9616):908-14. http://dx.doi.org/10.1016/S01406736(08)60416-X

27. Jacobs MR, Felmingham D, Appelbaum PC, Gruneberg RN. The Alexander Project 1998-2000: susceptibility of pathogens isolated from community-acquired respiratory tract infection to commonly used antimicrobial agents. J Antimicrob Chemother 2003;52(2):229-46. http://dx.doi.org/10.1093/jac/dkg321

28. Bayonne E, Kania R, Tran P, Huy B, Herman P. Intracranial complications of rhinosinusitis. A review, typical imaging data and algorithm of management. Rhinology 2009;47(1):59-65.

29. Aalokken TM, Hagtvedt T, Dalen I, Kolbenstvedt A. Conventional sinus radiography compared with CT in the diagnosis of acute sinusitis. Dentomaxillofac Radiol 2003;32(1):60-2. http://dx.doi.org/10.1259/dmfr/65139094

30. Yousem DM. Imaging of sinonasal inflammatory disease. Radiology 1993; 188(2):303-14.

\section{Available online at http://www.thepcrj.org}


R Hoffmans et al.

Appendix A. Questionnaire: Management of rhinosinusitis in general practice.

1. How long have you been practicing as a general practitioner?

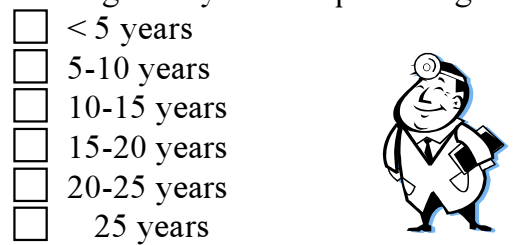

2. In what kind of practice do you work?

$\square$ Solo practice

$\square$ Duo practice

$\square$ Group practice

3. In which age group are you?
$\square<30$ years
30-34 years
35-39 years
40-44 years
45-49 years
50-54 years
55-59 years
60-64 years
65 years

4. From which duration of complaints would/do you speak of chronic rhinosinusitis?
$\square 1$ week
4 weeks
$\square 12$ weeks
$\square$ Half a year
$\square$ year

5. Do you differentiate between mild, moderate and severe complaints in your treatment of rhinosinusitis? YES

NO

6. Do you differentiate between acute and chronic complaints in your treatment of rhinosinusitis?

YES $\square$ NO

IF YOU ANSWERED QUESTION 6 WITH YES $\Longrightarrow$ PLEASE FILL OUT THE PINK QUESTIONNAIRE.

IF YOU ANSWERED QUESTION 6 WITH $\underline{N O}$

Ђ PLEASE FILL OUT

THE YELLOW QUESTIONNAIRE. 
Management of rhinosinusitis in Dutch general practice

Appendix A. Questionnaire: Management of rhinosinusitis in general practice continued.

\section{YOU DO DISCRIMINATE BETWEEN ACUTE AND CHRONIC RHINOSINUSITIS}

\section{The next questions are about acute rhinosinusitis.}

1. What percentage of your total patients has had a diagnosis of acute rhinosinusitis during the past 12 months? (choose one)

\begin{tabular}{|l|l}
$\square$ & $<2 \%$ \\
\hline$\square$ & $2-5 \%$ \\
$\square \square$ & $6-10 \%$ \\
$\square \square$ & $11-19 \%$ \\
$\square$ & $20 \%$ or more
\end{tabular}

2. Do you agree with the following statement?

For acute rhinosinusitis it is not recommended to take radiologic investigations.

$\square$ Agree

$\square$ Disagree, I usually request:

Plain X-ray $\square$, CT $\square$, Echo $\square$, others $\square \square$ (specify please)

aan.

Disagree, as I request CT scan only, in cases of patients with additional problems such as very severe, immuno-compromised patients with signs of complications.

3. In general, do you treat acute rhinosinusitis patients with symptoms less than 5 days?

$$
\text { YES } \square \text { NO } \square
$$

If YES, then what is you typical treatment plan? (check all that apply)

If you answer "yes" more than once, please rank order each treatment (1=most often, 10=least often)

a. Painkillers

Yes

Numbering

$(1-10)$

b. Antibiotics

(penicillin / amoxicillin-clavulanate / broad spectrum antibiotics)

Please specify the name, dosage and duration of antibiotics you have commonly used:
c. Topical antibiotics
d. Systemic steroids
e. Nasal steroids
f. Oral antihistamine
g. Decongestants
h. Nasal douche
i. Steaming
j. Mucolytics
k. Herbal medicine
1. Others (specify)

Yes Numbering

(1-10) 
R Hoffmans et al.

Appendix A. Questionnaire: Management of rhinosinusitis in general practice continued.

4. In general, do you treat patients with acute rhinosinusitis with moderate symptoms (no fever, no severe pain) which persist for more than 5 days?

JA $\square \quad$ NEE

If YES, then what is you typical treatment plan? (check all that apply)

If you answer "yes" more than once, please rank order each treatment ( $1=$ most often, 10=least often)

a. Painkillers

b. Antibiotics (penicillin / amoxicillin-clavulanate / broad spectrum antibiotics)

Yes

Numbering

Please specify the name, dosage and duration of antibiotics you have commonly used:
c. Topical antibiotics
d. Systemic steroids
e. Nasal steroids
f. Oral antihistamine
g. Decongestants
h. Nasal douche
i. Steaming
j. Mucolytics
k. Herbal medicine
1. Others (specify)

5. In general, do you treat patients with acute rhinosinusitis with severe symptoms (with fever $>38^{\circ} \mathrm{C}$ or severe pain)?

JA $\square \quad$ NEE

If YES, then what is you typical treatment plan? (check all that apply)

If you answer "yes" more than once, please rank order each treatment $(1=$ most often, $10=$ least often)

a. Painkillers

b. Antibiotics (penicillin / amoxicillin-clavulanate / broad spectrum antibiotics)

Yes

Numbering

Please specify the name, dosage and duration of antibiotics you have commonly used:
c. Topical antibiotics
d. Systemic steroids
e. Nasal steroids
f. Oral antihistamine
g. Decongestants
h. Nasal douche
i. Steaming
j. Mucolytics
k. Herbal medicine
1. Others (specify)

Yes Numbering 
Appendix A. Questionnaire: Management of rhinosinusitis in general practice continued.

6. What criteria do you typically use for referring each of the following types of acute rhinosinusitis patients to an ENT specialist?

a. Patients with moderate symptoms (choose one)

Always refer them to a specialist right after diagnosis

When no improvement occurs after 14 days of treatment

When no improvement occurs after 4 weeks of treatment

After one course of antibiotic treatment which did not work

After 48 hours with no effect of intranasal corticosteroids and/or antibiotics

Never refer them to a specialist

Other (specify):

b. Patients with severe symptoms (fever,pain) (choose one)

$\square$
$\square \quad$ When no improvement occurs after 14 days of treatment
When no improvement occurs after 4 weeks of treatment
After one course of antibiotic treatment which did not work
After 48 hours with no effect of intranasal corticosteroids and or antibiotics
Never refer them to a specialist
Other (specify):

c. Patients with ocular or neurological complications (choose one)

Always refer them to a specialist right after diagnosis

When no improvement occurs after 14 days of treatment

When no improvement occurs after 4 weeks of treatment

After one course of antibiotic treatment which did not work

After 48 hours with no effect of intranasal corticosteroids and/or antibiotics

Never refer them to a specialist

Other (specify):

\section{The next questions are about chronic rhinosinusitis.}

7. What percentage of your total patients has had a diagnosis of chronic rhinosinusitis during the past 12 months? (choose one)

\begin{tabular}{l}
$\square<2 \%$ \\
$\square 2-5 \%$ \\
$\square-10 \%$ \\
$\square 11-19 \%$ \\
\hline$\square 20 \%$ or more
\end{tabular}

8. Do you agree with the following statement?

For chronic rhinosinusitis it is not recommended to take radiologic investigations.

Agree

Disagree, I usually request:

Plain X-ray $\square$, CT $\square$, Echo $\square$, others $\square \_$_ (specify please)

aan.

Disagree, as I request CT scan only, in cases of patients with additional problems such as very severe, immuno-compromised patients with signs of complications. 
R Hoffmans et al.

Appendix A. Questionnaire: Management of rhinosinusitis in general practice continued.

9. In general, do you treat patients with chronic rhinosinusitis?

YES

NO

If YES, then what is you typical treatment plan? (check all that apply)

If you answer "yes" more than once, please rank order each treatment ( $1=$ most often, $10=$ least often)

a. Painkillers

b. Antibiotics

(penicillin / amoxicillin-clavulanate / broad spectrum antibiotics)

Yes Numbering (1-10)

Please specify the name, dosage and duration of antibiotics you have commonly used:

c. Topical antibiotics

Yes

Numbering

d. Systemic steroids

e. Nasal steroids

f. Oral antihistamine

g. Decongestants

h. Nasal douche

i. Steaming

j. Mucolytics

k. Herbal medicine

1. Others (specify)

10. After which duration of treatment do you reassess the complaints of a patient with chronic rhinosinusitits?
After 48 hours
After 14 days
After 4 weeks
After 12 weeks

11. What criteria do you typically use for referring chronic rhinosinusitis patients to an ENT specialist?

Always refer them to a specialist right after diagnosis

When no improvement occurs after 14 days of treatment

When no improvement occurs after 4 weeks of treatment

After one course of antibiotic treatment which did not work

After 48 hours with no effect of intranasal corticosteroids and/or antibiotics

Never refer them to a specialist

Other (specify):

12. Can we call you for an interview by telephone with 3 cases. This will take approximately 20 minutes.

YES

NO

Telephone:

Thank you very much for you cooperation in this survey! 
Appendix A. Questionnaire: Management of rhinosinusitis in general practice continued.

\section{YOU NOT DISCRIMINATE BETWEEN ACUTE AND CHRONIC RHINOSINUSITIS}

1. What percentage of your total patients has had a diagnosis of rhinosinusitis during the past 12 months? (choose one)

\begin{tabular}{|l|l}
$\square$ & $<2 \%$ \\
\hline$\square$ & $2-5 \%$ \\
\hline$\square$ & $6-10 \%$ \\
\hline$\square$ & $11-19 \%$ \\
$\square \quad 20 \%$ or more
\end{tabular}

2. Do you agree with the following statement?

For rhinosinusitis it is not recommended to take radiologic investigations.

$\square$ Agree

Disagree, I usually request:

Plain X-ray $\square$, CT $\square$, Echo $\square$, others $\square$ __ (specify please)

aan.

$\square$ Disagree, as I request CT scan only, in cases of patients with additional problems such as very severe, immuno-compromised patients with signs of complications.

3. In general, do you treat patients with rhinosinusitis with symptoms for less than 5 days?

If YES, then what is you typical treatment plan? (check all that apply)

If you answer "yes" more than once, please rank order each treatment $(1=$ most often, $10=$ least often)

a. Painkillers

Yes

Numbering

b. Antibiotics

(penicillin / amoxicillin-clavulanate / broad spectrum antibiotics)

Please specify the name, dosage and duration of antibiotics you have commonly used:
c. Topical antibiotics
d. Systemic steroids
e. Nasal steroids
f. Oral antihistamine
g. Decongestants
h. Nasal douche
i. Steaming
j. Mucolytics
k. Herbal medicine
1. Others (specify)

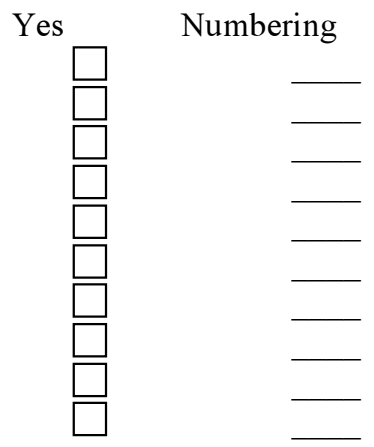


R Hoffmans et al.

Appendix A. Questionnaire: Management of rhinosinusitis in general practice continued.

4. In general, do you treat patients with rhinosinusitis with moderate symptoms (no fever, no severe pain) which persist more than 5 days?

YES

NO

If YES, then what is you typical treatment plan? (check all that apply)

If you answer "yes" more than once, please rank order each treatment (1=most often, $10=$ least often)

a. Painkillers

Yes

Numbering

$(1-10)$

b. Antibiotics

(penicillin / amoxicillin-clavulanate / broad spectrum antibiotics)

Please specify the name, dosage and duration of antibiotics you have commonly used:
c. Topical antibiotics
d. Systemic steroids
e. Nasal steroids
f. Oral antihistamine
g. Decongestants
h. Nasal douche
i. Steaming
j. Mucolytics
k. Herbal medicine
1. Others (specify)

5. In general, do you treat patients with rhinosinusitis with severe symptoms (with fever $>38^{\circ} \mathrm{C} \mathrm{o}$ severe pain)?

YES

NO

If YES, then what is you typical treatment plan? (check all that apply)

If you answer "yes" more than once, please rank order each treatment (1=most often, 10=least often)

a. Painkillers

Yes

Numbering

$(1-10)$

b. Antibiotics

(penicillin / amoxicillin-clavulanate / broad spectrum antibiotics)

Please specify the name, dosage and duration of antibiotics you have commonly used:
c. Topical antibiotics
d. Systemic steroids
e. Nasal steroids
f. Oral antihistamine
g. Decongestants
h. Nasal douche
i. Steaming
j. Mucolytics
k. Herbal medicine
1. Others (specify)

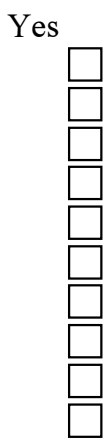

Numbering

(1-10) 
Appendix A. Questionnaire: Management of rhinosinusitis in general practice continued.

6. What criteria do you typically use for referring each of the following types of rhinosinusitis patients to an ENT specialist?

a. Patients with moderate symptoms (choose one)

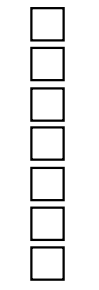

Always refer them to a specialist right after diagnosis

When no improvement occurs after 14 days of treatment

When no improvement occurs after 4 weeks of treatment

After one course of antibiotic treatment which did not work

After 48 hours with no effect of intranasal corticosteroids and/or antibiotics

Never refer them to a specialist

Other (specify):

b. Patients with severe symptoms (fever,pain) (choose one)

$\square \quad$ Always refer them to a specialist right after diagnosis

When no improvement occurs after 14 days of treatment

When no improvement occurs after 4 weeks of treatment

After one course of antibiotic treatment which did not work

After 48 hours with no effect of intranasal corticosteroids and/or antibiotics

Never refer them to a specialist

Other (specify):

c. Patients with ocular or neurological complications (choose one)

Always refer them to a specialist right after diagnosis

When no improvement occurs after 14 days of treatment

When no improvement occurs after 4 weeks of treatment

After one course of antibiotic treatment which did not work

After 48 hours with no effect of intranasal corticosteroids and/or antibiotics

Never refer them to a specialist

Other (specify):

7. Can we call you for an interview by telephone with 3 cases. This will take approximately 20 minutes.

YES

NO

Telephone:

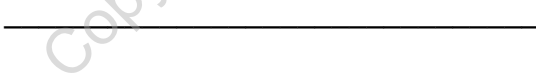

Thank you very much for you cooperation in this survey! 